\title{
Characterization of CoTi Intermetallic Materials Produced by Electric Current Activated Sintering
}

\author{
N. ERGIN AND O. OZDEMIR* \\ Sakarya University, Technology Faculty, Department of Metallurgy and Materials Engineering \\ Esentepe Campus, 54187, Sakarya, Turkey
}

\begin{abstract}
In the present work, the characterization and production of CoTi intermetallic materials produced by electric current activated sintering under $300 \mathrm{MPa}$ uniaxial pressure in open air at $2000 \mathrm{~A}$ for 6 min was investigated. Cobalt powder with $10 \mu \mathrm{m}$ size and titanium powder $<40 \mu \mathrm{m}$ size having $99.9 \%$ and $99.5 \%$ purity, respectively, were used. The elemental powders were mixed in the stoichiometric ratio corresponding to the CoTi intermetallic, in a molar proportion of 1:1. Scanning electron microscopy and X-ray diffraction analysis were used to characterize produced samples. In microstructural examinations it was found that the sample has multi-phase microstructure. X-ray diffraction studies revealed that the phases are $\mathrm{CoTi}, \mathrm{CoTi}_{2}, \mathrm{TiCo}_{2}$, and $\mathrm{CoTiO}_{3}$. The relative density of test materials measured according to Archimedes' principle was $87.6 \%$, and the microhardness of materials was about $646.74 \mathrm{HV}_{0.1}$.
\end{abstract}

DOI: 10.12693/APhysPolA.125.399

PACS: $81.20 . \mathrm{Ev}, 81.40 . \mathrm{Pq}$

\section{Introduction}

Intermetallic compounds and ordered intermetallic phases have been the subject of scientific interest for more than 50 years because of their attractive physical, thermal, and mechanical properties. These materials are gradually becoming a new class of structural materials as they are in certain aspects better than conventional alloys and safer than ceramics. Many intermetallic materials exhibit the $B 2$-type crystal structure, for example several aluminides (such as $\mathrm{NiAl}, \mathrm{FeAl}$, and $\mathrm{CoAl}$ ) and titanides (such as NiTi, FeTi, and CoTi). Ordered B2-type intermetallic materials have generally high melting point, good corrosion resistance, high phase stability and excellent oxidation resistance that make them a promising high-temperature structural material.

Among many ordered B2-type intermetallic materials, CoTi is stable up to melting point $\left(1325^{\circ} \mathrm{C}\right)$, and also has strong yield anomaly strength, unique shape memory properties and noticeable room and high-temperature ductility. Up to now, several processes including thermal explosion, laser melting deposition, self-propagating high-temperature synthesis (SHS), and melting and crystal growth have been applied for production of CoTi intermetallic materials.

Among these, electric current activated/assisted sintering (ECAS) technique, Fig. 1, loose powders or a cold formed compact to be consolidated are inserted into a container which is heated to and then held at the desired temperature, while pressure is applied and maintained for a given period of time. Heat is provided by passing an electric current through the powders and/or their container, thus exploiting the consequent Joule effect.

\footnotetext{
*corresponding author; e-mail: oozdemir@sakarya.edu.tr
}

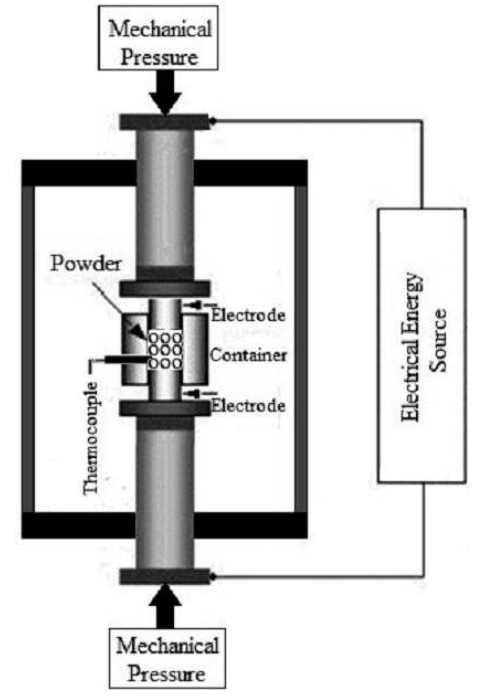

Fig. 1. Schematic representation of the ECAS process.

On the contrary, in conventional HP techniques, the powder container is typically heated by radiation from the enclosing furnace through external heating elements and convection of inert gases if applicable. Therefore, the sample is heated as a consequence of the heat transfer occurring by conduction from the external surface of the container to the powders. The resulting heating rate is then typically slow and the process can last hours. In addition, a lot of heat is wasted as the whole volume of space is heated and the compact indirectly receives heat from the hot environment. On the other hand, ECAS processes are characterized by the efficient use of the heat input, particularly when electrically insulating container is used and the electric current is applied for extremely short duration (down to few hundreds of microseconds) [1-10]. 
In this study, CoTi intermetallic materials were produced by electric current activated/assisted sintering method and its properties were also investigated using various techniques including scanning electron microscopy (SEM) and X-ray diffraction (XRD). In order to determine hardness and density of the test materials, a Vickers indenter and Archimedes' technique were utilized.

\section{Experimental produce}

Cobalt powder ( $99.9 \%$ purity, $10 \mu \mathrm{m})$, titanium powder $(99.5 \%$ purity, $<40 \mu \mathrm{m})$ were used as starting materials in order to manufacture $\mathrm{Co}-\mathrm{Ti}$ intermetallic compound. Co and Ti powders were mixed in stoichiometric ratio corresponding to the CoTi intermetallic phase, in a molar proportion of 1:1. Prior to sintering, the mixture was cold pressed into a cylindrical compact in a metal die under $300 \mathrm{MPa}$ uniaxial pressure. The diameter and height of the compact samples were $15 \mathrm{~mm}$ and $5 \mathrm{~mm}$, respectively. The production of CoTi intermetallic materials was performed by electric current activated sintering at a maximum of $2000 \mathrm{~A}$ for 6 min.

The relative density and porosity of the synthesized sample were measured using Archimedes' method. The microstructures and phase constitutions were characterized by SEM-energy dispersive spectroscopy (SEM-EDS), XRD. Microhardness of sintered test materials was determined by using micro-hardness tester with a load of $100 \mathrm{~g}$ for $10 \mathrm{~s}$ on polished cross-sectional area of test materials.

\section{Results and discussion}

The microstructure of $\mathrm{CoTi}$ intermetallic materials produced by electric current activated sintering method was confirmed by SEM examinations (Fig. 2). SEM analysis studies showed that the test material has multi-phase and dense microstructure.

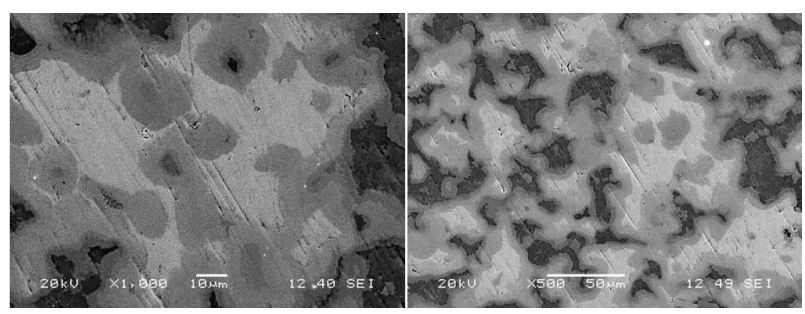

Fig. 2. SEM images of CoTi sample.

$\mathrm{X}$-ray diffraction (XRD) technique was used in order to identify the phases in the sample which was sintered under $300 \mathrm{MPa}$ uniaxial pressure in open air at $2000 \mathrm{~A}$ for 6 min. The XRD patterns of test material indicate that the $\mathrm{CoTi}, \mathrm{CoTi}_{2}, \mathrm{TiCo}_{2}$ and $\mathrm{CoTiO}_{3}$ phases are present in the sample (Fig. 3).

The distribution of alloying elements in the samples was determined by EDS analysis as shown in Fig. 4. Dot analysis was carried out by EDS and revealed that Mark 1 is consisting of $31.4 \mathrm{wt} \% \mathrm{Ti}, 68.6 \mathrm{wt} \% \mathrm{Co}$, Mark 2 is consisting of $1.949 \mathrm{wt} \% \mathrm{Ti}$ and $98.051 \mathrm{wt} \% \mathrm{Co}$, Mark 3 is consisting of $95.442 \mathrm{wt} \% \mathrm{Ti}$ and $4.558 \mathrm{wt} \% \mathrm{Co}$, Mark 4 is consisting of $64.983 \mathrm{wt} \% \mathrm{Ti}$ and $35.017 \mathrm{wt} \% \mathrm{Co}$.

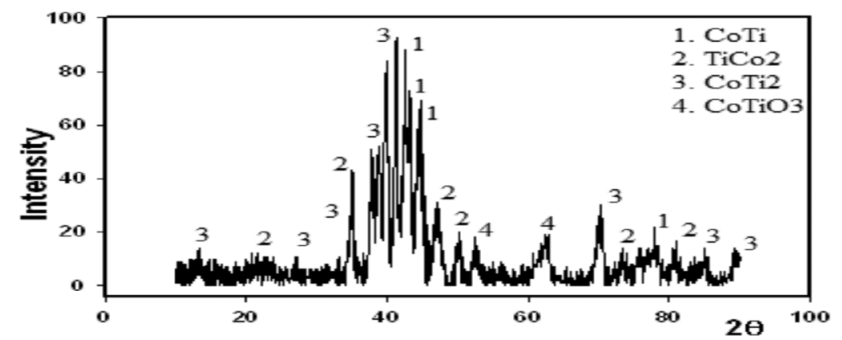

Fig. 3. XRD patterns of CoTi.

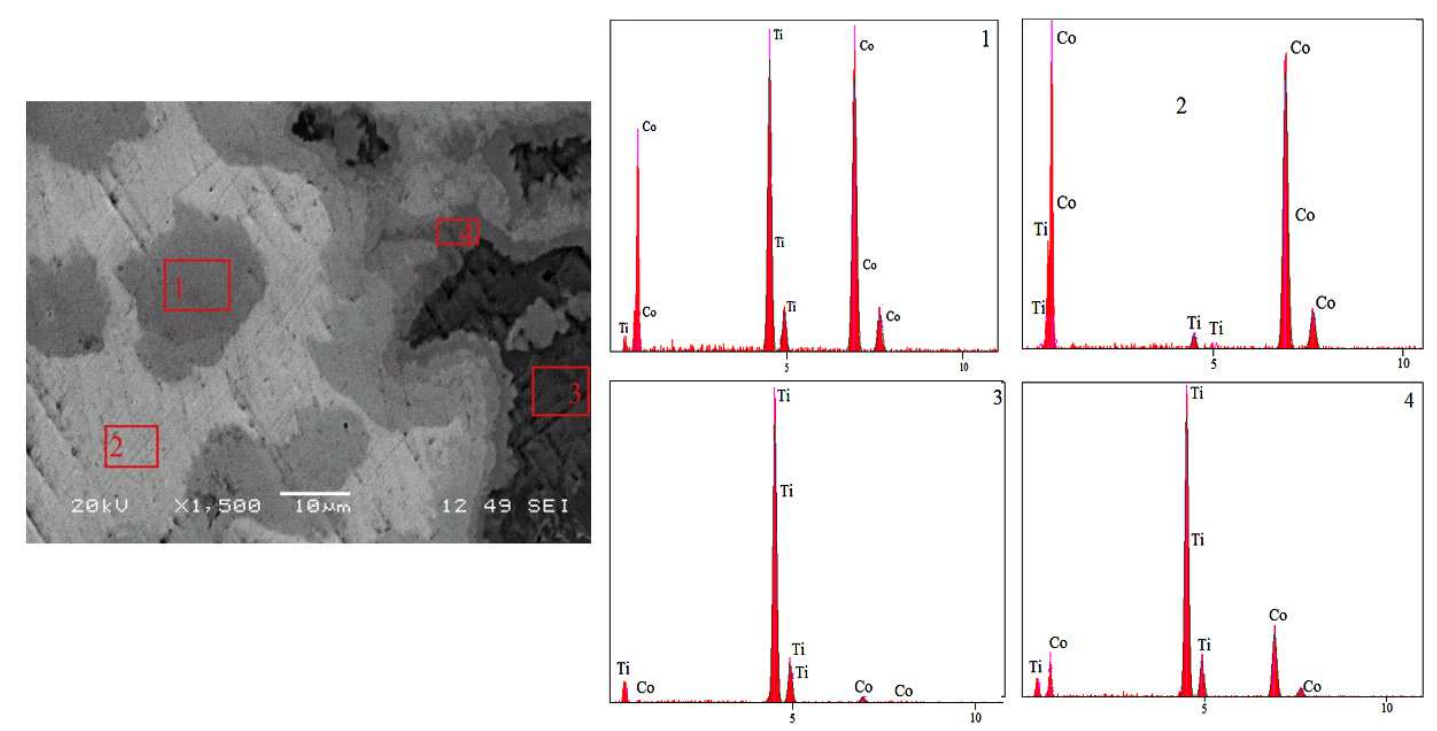

Fig. 4. EDS analyses of test material. 
The hardness of CoTi samples measured using Vickers indentation technique was about approximately $646.74 \mathrm{HV}_{0.1}$. The relative densities of the samples calculated according to Archimedes' principle was approximately $87.6 \%$.

\section{Conclusions}

The CoTi intermetallic material produced by electric current activated sintering has multi-phase and low porosity. The presence of $\mathrm{CoTi}, \mathrm{CoTi}_{2}, \mathrm{TiCo}_{2}$ and $\mathrm{CoTiO}_{3}$ phases were confirmed by XRD analysis. The relative density is $87.6 \%$ for CoTi intermetallics materials. The microhardness of materials measured by Vickers indenter was about $646.74 \mathrm{HV}_{0.1}$.

\section{References}

[1] C. Sierra, A.J. Vazquez, Intermetallics 14, 848 (2006).
[2] C.L. Yeh, C.C. Yeh, J. Alloys Comp. 396, 228 (2005).

[3] R.P. Mulay, S.R. Agnew, Acta Mater. 60, 1784 (2012).

[4] M. Wittmann, I. Baker, Mater. Sci. Eng. A 329331, 206 (2002).

[5] Y. Kaneno, T. Takasugi, Mater. Sci. Eng. A 302, 215 (2001).

[6] A. Molladavoudi, S. Amirkhanlou, M. Shamanian, F. Ashrafizadeh, Mater. Lett. 81, 254 (2012).

[7] N. Ergin, G. Yoruk, O. Ozdemir, Acta Phys. Pol. A 123, 245 (2013).

[8] J. Rodriguez, S.O. Moussa, J. Wall, K. Morsi, Scr. Mater. 48, 707 (2003).

[9] R. Orru, R. Licheri, A.M. Locci, A.G. Cincotti, Mater. Sci. Eng. R 63, 127 (2009).

[10] J. Liu, Y. Yang, K. Feng, D. Lu, J. Alloys Comp. 476, 207 (2009). 